\title{
28-year late spermatic cord relapse of a testicular non-seminomatous germ cell tumour, managed robotically
}

\author{
James R. Hayes; Michael A.S. Jewett, MD; Robert J. Hamilton, MD, MPH \\ Department of Surgical Oncology (Urology), Princess Margaret Cancer Centre, Toronto, ON, Canada
}

Cite as: Can Urol Assoc J 2016;10(7-8):E257-60. http://dx.doi.org/10.5489/cuai.3492 Published online July 12, 2016

\section{Abstract}

We present a patient who relapsed symptomatically 28 years postorchiectomy, initially followed by active surveillance for clinical stage I non-seminomatous germ cell tumour (CSI NSGCT). His relapse was localized to the pelvis, managed with robotic surgery, and achieved a complete resection with tumour markers normalized. We highlight the current Princess Margaret guidelines for followup of CSI NSGCT and discuss the trade-off between lifelong radiographic surveillance to detect the very small risk of late relapse. We discuss the incidence and presentation of late relapse, treatment options, and outcomes, highlighting that these tumours are typically refractory to chemotherapy and can often be managed with surgery alone.

\section{Introduction}

Options for management of clinical stage I nonseminomatous testicular germ cell tumours (CSI NSGCTs) include active surveillance, chemotherapy (consisting of bleomycin, etoposide, and cisplatin for one or two cycles), or retroperitoneal lymph node dissection (RPLND). Active surveillance is offered for low-risk patients (CSIA) in most centres, but controversy exists about the preferred management in high-risk CSI NSGCT (typically defined by the presence of lymphovascular invasion, pure embryonal carcinoma, and rete testis invasion in the primary tumour).

At the Princess Margaret Cancer Centre, all CSI NSGCT patients, regardless of risk, have been offered active surveillance as initial management since 1981. ${ }^{1,2}$ This has proven an effective strategy to maintain high survival and minimize morbidity. As a result, this approach has been recommended by several guidelines and adopted by many other centres worldwide. ${ }^{1,3-5}$

The current active surveillance protocol for CSI NSGCT at Princess Margaret involves regular and structured monitoring of tumour markers (alpha-fetoprotein [AFP], human chorionic gonadotropin [hCG], lactate dehydrogenase [LDH]) and computed tomography (CT) scans of the chest, abdomen, and pelvis, and has been previously outlined in the literature. ${ }^{1,6}$ After two years of active surveillance, the intensity is tapered. After five years, most patients with no evidence of disease are now discharged from further followup to their primary care provider. ${ }^{1,6}$ Good evidence exists to stop after five years because our subsequent relapse risk has been very low. In a pooled analysis of 938 men with CSI NSGCT managed with active surveillance, only $1 \%$ experienced relapse after three years of post-orchiectomy surveillance. ${ }^{3}$

Overall, the relapse rate for CSI NSGCT is $26-35 \% .^{1,3,6-8}$ The most likely site of relapse is the retroperitoneum, followed less frequently by the lung. ${ }^{1}$ Most (90\%) CSI NSGCT relapses, occur within two years, with a median time to relapse typically around 6-7 months..$^{1,3,4}$ Relapses beyond two years are considered late relapse and are much less common. A 2007 systematic review of testicular GCT surveillance found only seven reported recurrences after five years of surveillance, with a maximum time to relapse of 14.25 years. ${ }^{7}$ In our 2011 update on active surveillance data, we reported two cases of late relapse at 12 and 14 years. ${ }^{1}$ Additionally, a literature search found an additional two cases of very late relapse (32 and 43 years). ${ }^{9,10}$ The nature of late relapse CSI NSGCT biology means that patients who relapse are commonly symptomatic and present most often with abdominal pain..$^{9,11,12}$

\section{Case report}

We present a rare case of a 28-year post-orchiectomy late relapse in a 50-year-old male who underwent left radical orchiectomy in 1987. His pathology showed pure embryonal histology with lymphovascular invasion, stage pT2. His staging CT scan was negative, as were his chest X-ray and pre- and postoperative serum tumour marker assessments. Thus, he was CSIB and managed according to the Princess Margaret active surveillance guidelines. He was discharged 
Hayes et al.

to his primary care physician after eight years of surveillance without evidence of disease.

In February 2015, he presented to a local hospital with complaints of left lower quadrant abdominal pain suspicious for diverticulitis. A non-contrast CT of the abdomen and pelvis revealed a $2.5 \times 2.0 \mathrm{~cm}$ mass lateral to the sigmoid colon in the left lower quadrant. Followup at Princess Margaret included a repeat CT scan confirming a mass along the left vas deferens adjacent to the external iliac vessels (Fig. 1). Serum tumour markers showed normal hCG and LDH, but elevated AFP $(110 \mu \mathrm{g} / \mathrm{L}$; normal <6). Physical exam was unremarkable.

After multidisciplinary discussion of options, including chemotherapy and open/laparoscopic/robotic mass excision \pm full bilateral RPLND, the patient elected robotic mass excision. Port placement followed a template similar to that used for robotic prostatectomy, with slight migration cephalad and contralateral to the mass. Dissection included removal of the mass and remnant spermatic cord (Fig. 2) extending into the inguinal canal and proximally up to the level of the lower pole of the kidney. Additionally, a left pelvic lymph node dissection was performed, with limits from the genitofemoral nerve laterally, to the hypogastric artery medially, to the obturator fossa posteriorly, and the node of cloquet inferiorly and proximally to include para-aortic tissue up to the level of the lower pole of the left kidney. A mesh repair using spiral titanium tacks was conducted to reinforce the region around the left inguinal canal. Intraoperative photos are presented (Fig. 2).

The procedure was conducted without complications and the patient's postoperative course in hospital was unremark- able. Pathological analysis of the mass revealed a $2.9 \mathrm{x}$ $3.7 \times 3.3 \mathrm{~cm}$ yolk sac tumour and there was a previously undetected, single positive lymph node containing metastatic seminoma with no extranodal extension. The surgical margins were negative for malignancy. At 14 months followup, our patient remains free of disease with normal tumour markers

\section{Discussion}

Our patient presents an extremely rare case of 28-year postorchiectomy relapse of a CSI NSGCT in the spermatic cord. To our knowledge, only two later cases have been reported ${ }^{9,10}$ and only $1 \%$ of patients will relapse three or more years postorchiectomy. ${ }^{3}$ This case and other rare late relapse cases raise the question of whether lifetime imaging surveillance should be performed for CSI NSGCT patients. With the documented risks of radiation exposure associated with $\mathrm{CT}$ scans, the cost to the healthcare system that would be incurred by serial imaging, and the relative rarity of late relapses, we and others continue to support a policy of discharging patients after five years of surveillance, knowing there is a small $(<1 \%)$ risk of late relapse. Additionally, predicting the time to relapse past two years is difficult. ${ }^{3}$ Fortunately, it appears that most patients with late-relapsing GCT present symptomatically, ${ }^{9,11-14}$ most commonly with abdominal pain, as seen in this patient and other patients previously described. ${ }^{1}$ Moreover, late relapses typically can be managed surgically. ${ }^{11}$ In a recent large multicentre cohort report of CSI NSGCT on surveillance, there were no deaths from disease or treatment in patients relapsing after two years.
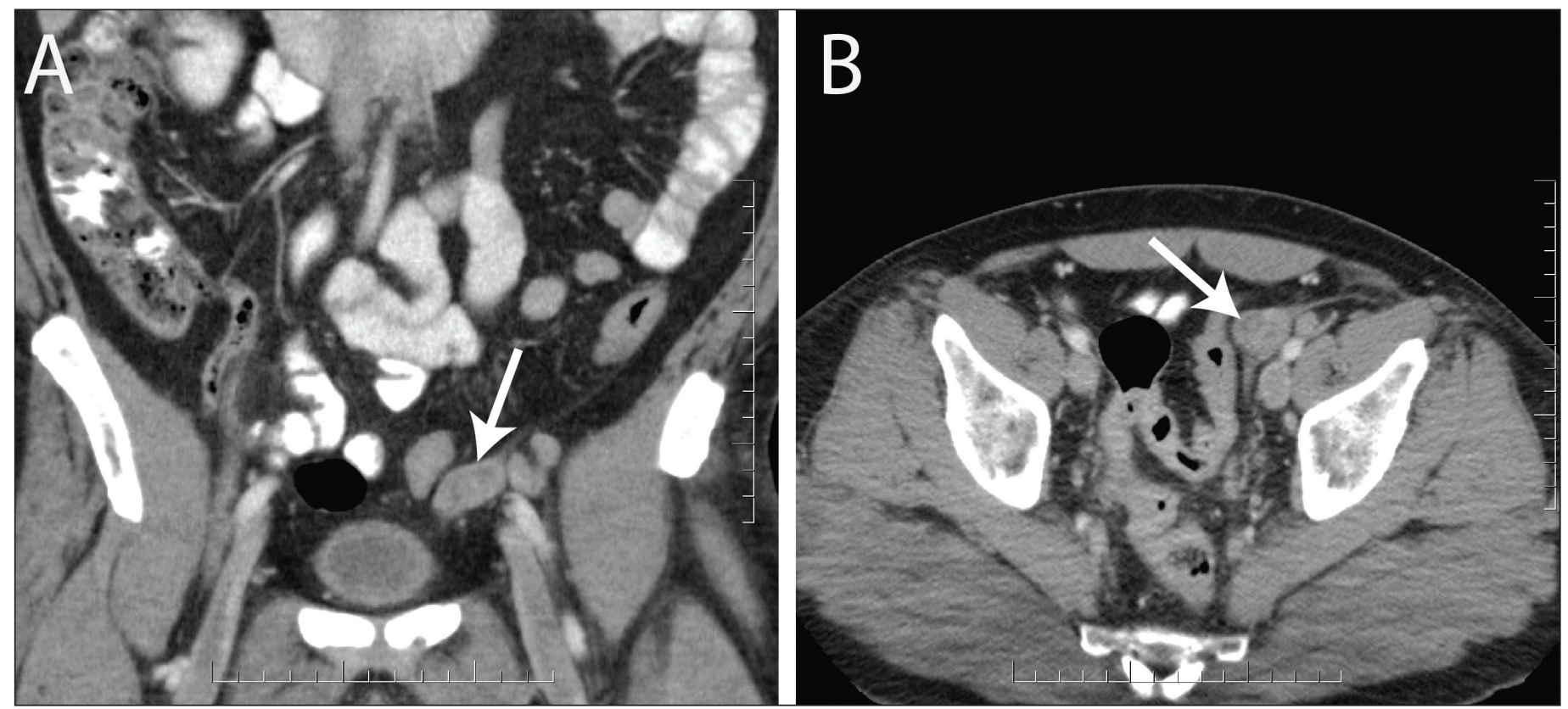

Fig. 1. Coronal (A) and axial (B) computed tomography scans of abdomen and pelvis with arrow indicating location of left pelvic mass emanating from spermatic cord. 

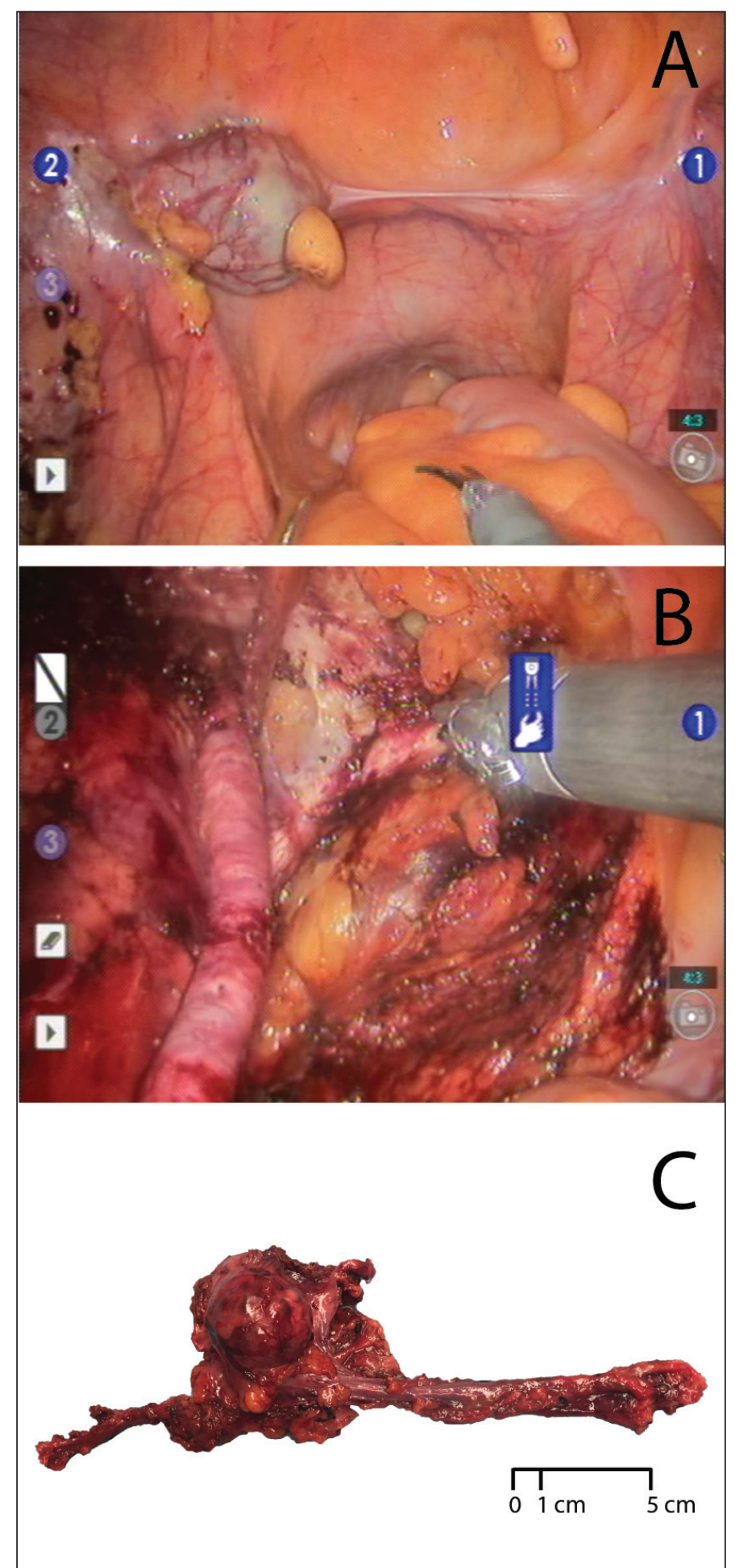

Fig. 2. (A) Intraoperative pre-dissection photo of tumour in situ in the left lower quadrant, lateral to the sigmoid colon; $(\boldsymbol{B})$ Intraoperative photo demonstrating the mass now excised; left external iliac and left superior pubic ramus exposed; left inguinal canal opened; left inferior epigastric vessels preserved; (C) Resected tumour and spermatic cord; distal cord remnant on left and proximal on right.
The decision to manage this case with a local mass excision only and no systemic therapy arises from the long natural history favouring an inability of the tumour to metastasize distantly. Relapsing GCTs are also typically resistant to chemotherapy ${ }^{11}$ and often include a component of teratoma, which is intrinsically chemotherapy-resistant. ${ }^{15}$ The decision to manage this case robotically was made in part based on the localization of the mass, allowing a similar surgical approach to that used for prostatectomies. Robotic surgery is being used more broadly in urology and its application now includes RPLND. ${ }^{16,17}$

Competing interests: Mr. Hayes declares no competing personal or financial interests. Dr. Jewett has been an Advisory Board member for Novartis, Pfizer, and Theralase; has received grants/honoraria from GSK, Novartis, and Pfizer; holds investments in Theralase; and has participated in clinical trials for GSK, Novartis, and Pfizer. Dr. Hamilton has been an Advisory Board member for AbbVie, Astellas, Bayer, and Janssen; and has participated in clinical trials for Janssen.

This paper has been peer-reviewed.

\section{References}

1. Sturgeon JF, Moore MJ, Kakiashvili DM, et al. Non-risk-adapted surveillance in clinical stage I nonseminomatous germ cell tumours: The Princess Margaret Hospital's experience. Eur Urol 2011;59:556-62. http://dx.doi.org/10.1016/i.eururo.2010.12.010

2. Jewett MA. Nonoperative approach for the management of clinical stage A non-seminomatous germ cell tumours. Semin Urol 1984:2:204-07.

3. Kollmannsberger C, Tandstad T, Bedard PL, et al. Patterns of relapse in patients with clinical stage I testicular cancer managed with active surveillance. J Clin Oncol 2015;33:51-7. http://dx.doi.org/10.1200/ JC0.2014.56.2116

4. Daugaard G, Gundgaard MG, Mortensen MS, et al. Surveillance for stage I non-seminoma testicular cancer: Outcomes and long-term followup in a population-based cohort. J Clin Oncol 2014;32:3817-23. http:// dx.doi.org/10.1200/JC0.2013.53.5831

5. Wood $L$, Kollmannsberger $C$, Jewett $M$, et al. Canadian consensus guidelines for the management of testicular germ cell cancer. Can Urol Assoc J 2010;4:e19-e38.

6. Sharir $\mathrm{S}$, Jewett MA, Sturgeon JF, et al. Progression detection of stage I non-seminomatous testis cancer on surveillance: Implications for the followup protocol. J Urol 1999;161:472-6. http://dx.doi. org/10.1016/S0022-5347(01)61926-8

7. Groll RJ, Warde P, Jewett MAS. A comprehensive systematic review of testicular germ cell tumour surveillance. Crit Rev Oncol Hematol 2007;64:182-97. http://dx.doi.org/10.1016/i.critrevonc.2007.04.014

8. Read G, Stenning SP, Cullen MH, et al. Medical Research Council prospective study of surveillance for stage I testicular teratoma. Medical Research Council Testicular Tumours Working Party. JC0 1992;10:1762-68.

9. Pavic M, Meeus P, Treilleux I, et al. Malignant teratoma 32 years after treatment of germ cell tumour confined to testis. Urology 2006;67:846.e1 1-846.e13. http://dx.doi.org/10.1016/i.urology.2005.10.039

10. Mukhtar $S$, Beatty J, Agrawal $S$, et al. Germ cell tumour: Late recurrence after 43 years. Ann $R$ Coll Surg Engl 2011;93:e24-e26. http://dx.doi.org/10.1308/147870811X580442

11. Ehrlich Y, Rosenbaum E, Baniel J. Late relapse of testis cancer. Curr Urol Rep 2013;14:518-24. http:// dx.doi.org/10.1007/s11934-013-0355-4

12. Pezaro CJ, Mallesara G, Toner GC. Late relapsing stage I non-seminoma. JCO 2008;26:5502-3. http:// dx.doi.org/10.1200/JC0.2008.19.3417

13. Ronnen EA, Kondagunta GV, Bacik J, et al. Incidence of late-relapse germ cell tumour and outcome to salvage chemotherapy. JCO 2005;23:6999-7004. http://dx.doi.org/10.1200/JC0.2005.21.956

14. George DW, Foster RS, Hromas RA. Update on late relapse of germ cell tumour: A clinical and molecular analysis. JCO 2003;21:113-22. http://dx.doi.org/10.1200/JC0.2003.03.019

15. O'Shaughnessy MJ, Feldman DR, Carver BS, et al. Late relapse of testicular germ cell tumours. Urol Clin North Am 2015;42:359-68. http://dx.doi.org/10.1016/i.ucl.2015.04.010 
Hayes et al.

16. Harris $K T$, Gorin $M A$, Ball MW, et al. A comparative analysis of robotic vs laparoscopic retroperitoneal lymph node dissection for testicular cancer. BJU Int 2015;116:920-3. http://dx.doi.org/10.1111/bju.13121

17. Williams SB, Lau CS, Josephson DY. Initial series of robot-assisted laparoscopic retroperitoneal lymph node dissection for clinical stage I non-seminomatous germ cell testicular cancer. Eur Urol 2011;60:1299-1302. http://dx.doi.org/10.1016/j.eururo.2011.03.009
Correspondence: Dr. Robert J. Hamilton, Department of Surgical Oncology (Urology), Princess Margaret Cancer Centre, Toronto, ON, Canada; rob.hamilton@uhn.ca 